\title{
STUDYING ENTERPRISE SYSTEMS' ACCEPTANCE USING INTEGRATED UNIFIED THEORY OF ACCEPTANCE AND USE OF TECHNOLOGY (UTAUT)
}

\author{
HART AWA*1 AND KALU UKOHA ${ }^{2}$ \\ ${ }^{1}$ Department of Marketing, University of Port Harcourt. East/West Road, OMB 5323 Choba, Rivers State, Nigeria. ${ }^{2}$ University \\ of Nigeria, Enugu Campus, Nigeria.
}

*Corresponding author: awa.hartouph@yahoo.com

Submitted final draft: 28 December 2019 Accepted: 11 January 2020

http://doi.org/10.46754/jssm.2020.07.010

\begin{abstract}
This paper proposes framework within unified theory of acceptance and use of technology, task-technology fit and perceived trust to reposition consumer-context and assure need-fit and security in enterprise system adoption. Survey data were collected from a purposive sample of 191 executives of fast-food firms, and analysis and empirical findings were based on multiple regressions and partial-least square. The results indicate that within the proposed framework, an approximated 57 percent of variance on ES adoption was explained by the predictors with acceptable fit indices and significant relationships between variables. All the path coefficients were statistically supported with the paths of facilitating conditions and task interdependence to adoption being the most critical predictors, and complexity to adoption having a negative significant coefficient - a unit increase attracts less adoption likelihoods or vice versa. The integrated model is critical to the understanding of ES adoption and implies on the operational ordeals of the individual models and reinforces improving skills and infrastructural facilities, interpersonal communications amongst audiences, and service quality to reflect trust and task demands.
\end{abstract}

Keywords: ES, Information management, adoption, SMEs.

\section{Introduction}

The surge in the global use of internet-based technologies and IT innovations from over 14 million in 1993 to over 3 trillion in 2016 (Internet Live Stats, 2016) is critical for socioeconomic growth. Studies linked internet use to national income and social accounting, corporate performance, and individual productivity (Makokha \& Ochieng, 2014). However, enterprise systems (ES) is one of such customized IT innovations whose buzz in different contexts has tremendously affected inter-and-intra-firm alignment and customer service delivery (Awa, 2019). Scholars (Martins et al., 2014; Thomas et al., 2014; Yurdakul et al., 2014) posit that an integrated ES solution builds competitive advantages for firms, given that it strategically completes order management, inventory control and warehouse management, quality control processing, advanced forecasting and material requirement planning (MRP), manufacturing, financial management, CRM, business intelligence, payroll, catch weight processing, and e-commerce functionality.
ES tracks day-to-day business activities and schedules staff to meet up with customer demands. Despite these, many entities are still behind in ES adoption owing to many factors. Studies on the diffusion of technologies seem endless and mature in some economies (Venkatesh et al., 2012) because of countless stakeholders' perspectives, technologies and contexts, units of analysis, theories and research plans (Williams et al., 2015). Williams et al. (2015) and Tarhini et al. (2016) show that IS models explain differently the relationship amongst attributes, contextual factors, beliefs, attitudes and intentions; and almost threw analysts into confusion. Venkatesh et al. (2003) attempted to unequivocally harmonize adoption views, and to reduce the confusion therein when they subsumed and collapsed eight alternative theories into unified theory of acceptance and use of technology (UTAUT).

The initial version of the UTAUT article captured performance expectancy (PE), effort expectancy (EE), social influence (SI) and facilitating conditions (FC) as the core 
determinants of intention and behaviour in any contexts; and voluntariness of use and some demographic factors served as moderators (Venkatesh et al., 2003; Williams et al., 2015; Tarhini et al., 2015). Although, the eight models earn robust theoretical and/or empirical supports, as well as validated inventory of psychometric measurements and underpin many IS studies (Venkatesh et al., 2012; Tarhini et al., 2016), the hybrid strength of UTAUT outweighs the solo effects of each in explaining adoption (Venkatesh et al., 2012). UTAUT is well-celebrated for its simplicity, parsimony and robust lenses into understanding adoption (Tarhini et al., 2016), given its extensive crosseconomy acceptance, and diverse-context supports (Kamoun \& Almourad, 2014; Martins et al., 2014; Yurdakul et al., 2014; Tarhini et al., 2016). However, more research is still needed to review the performance of UTAUT and/ or to reassess its findings, limitations or future directions (Williams et al., 2015) in keeping with Alvesson and Karreman's (2007) demand for critical advancement of theories. Scholars (Venkatesh et al., 2012; Awa \& Ojiabo, 2016) opine that irrespective of the growing scholarly encomiums for many IS frameworks and given that everything changes overtime, all yearn for continual systematic inquiry and theorizing that reflect factor extension and wider context uses, as well as replication to improve their theoretical and practical strengths.

Dwivedi et al. (2017) applauded the original UTAUT for its considerable amount of variance in intention and use, though they blamed it for theorizing some relationships that rarely apply to all contexts, for omitting some potentially important relationships, and for excluding some crucial constructs that explain acceptance. UTAUT rarely gives sufficient explanation on adoption of new technologies in a voluntary context, given its initial focus on large enterprisecontext adoption (Venkatesh et al., 2003; Venkatesh et al., 2012). Further, the moderators specified in the original UTAUT seldom enjoy cross-context epoch, and the omission of attitude and the path from facilitating conditions to intention is a bit worrisome. Therefore, the research community is in dire need for improved UTAUT framework that integrates other cognate models in order to address customer needs and/ or customer-context issues in an environment characterized, amongst others, by competition, informed market, and product obsolescence. Alatawi et al. (2012) posit that to identify specific factors within the contexts and to establish the underlying relationships amongst the factors, UTAUT requires integrating other adoption theories to have more comprehensive theoretical lenses. Studies (Alalwan et al., 2018; Choudrie et al., 2018; Holzmann et al., 2018) show that UTAUT and UTAUT2 frameworks seem reticent on the issues of perceived trust (PT) and its connection with privacy and security, as well as the degree to which there are symmetric fits between technology's tasks and customer needs. PT allays the fears of insecurity in virtual setting (Awa et al., 2015a; Tarhini et al., 2016; Alalwan et al.,), given that on-line transactions are often besieged with privacy, safety and security concerns. Within customercontext, trust is a critical determinant of intention to use (Hanafizadeh et al., 2014; Alalwan et al., 2018) and without technology's fits with tasks, actual usage rarely gives full adoption picture (Goodhue \& Thompson, 1995).

The a priori expectation is that integrating UTAUT with customer-context architecture complements and/or extends extant factors and builds more encompassing theoretical framework that offers improved innovative thoughts and prediction of technology acceptance/use. Task-technology-fit (TTF) and PT factors are connected to perceived credibility since in customer-context; they determine the possibility of engaging in web transactions (Yousafzai et al., 2010; Kesharwani \& Bisht, 2012). Kesharwani \& Bisht (2012) opine that the high uncertainty, intangibility, heterogeneity, discomfort and insecurity, and sometimes vague outcomes of some online transactions inhibit customers' confidence and adoption readiness. Similarly, technology's capability to address specific needs serves as critical adoption factor - technology must fit user's needs and improve performance for it to gain user endorsement 
(Goodhue and Thompson, 1995: Dishaw \& Strong, 1999; D'Ambra et al., 2013). This paper advances knowledge further and identifies future research directions by attempting to critically review and extend UTAUT framework. It proposes a framework that integrates UTAUT with TTF and PT factors, and tested it in attempt to factor-in customer-context epoch, to unveil the individual and integrated strengths of factors in explaining adoption, and to improve upon UTAUT's theoretical utilities. This paper is structured to reflect a review and proposition of theoretical framework, research approach and data collection, testing the proposed framework, discussion and conclusion.

\section{UTAUT and Study Framework}

The analysis of alternative adoption theories, especially the precursors of UTAUT, exposes myriad of similar constructs and the decision to choose the most context-specific ones. UTAUT is a compendium of theories made of four core determinants of intention and use and four moderators of key relationships based on such analysis of constructs. Venkatesh et al. (2003) integrated the competing adoption theories TRA, TAM, Motivational Model (MM), TPB, combined TAM and TPB(C-TAM-TPB), MPCU, IDT and SCT. TRA assumes human behaviour is driven by intention, which is a function of attitude and subjective norms (Ajzen, 1991). However, Dwivedi et al. (2017) observe that the snags of TRA informed the theoretical directions of Ajzen's (1991) more comprehensive TPB and Davis' (1989) more parsimonious and widely used TAM. TAM explains adoption in terms of perceived usefulness (PU) and perceived ease of use (PEOU); while TPB added perceived behavioural control as a critical determinant in order to make up for Ajzen's (1991) ordeal of not dealing with behaviours where people have full volitional control. Further studies proposed a hybrid model of elements of TAM and TPB (C-TAM-TPB) in Decomposed Theory of Planned Behaviour (DTPB) to predict intention; similar to TAM and in contrast with TPB, DTPB decomposed attitude, subjective norm, and perceived behavioural control into the belief structure of adoption (Taylor \& Todd, 1995; Venkatesh et al., 2003). Venkatesh \& Davis (2000) extended TAM to TAM2 to accommodate subjective norm as an additional predictor of intention in the case of a compulsory setting. Although Thompson et al. (1991) refined the model in the light of IS/IT adoption context, the model of perceived credibility utilization (MPCU), which largely originates from Triandis' (1977) theory of human behaviour competes with the propositions of TRA and TPB frameworks.

Rogers' (2003) IDT proposed five generic attributes of innovation that influence adoption - relative advantage, complexity, compatibility, observability, and trial ability; and Bandura (2010) assumed social cognitive theory (SCT) to recognize the interface of individual factors, behaviour, and environment on behaviour. Venkatesh et al. (2003) found that these eight models integrated explained about 17 and 53\% variance in intention; and outperformed all the eight models individually; and explained about $70 \%$ of variance in intention using the same data. UTAUT is celebrated and has leveraged context extension theories (Alvesson \& Karreman, 2007; Venkatesh et al., 2012), especially when Venkatesh et al. (2012) added hedonic motivation, habit and price-value in their more cohesive UTAUT2. It enjoys robust theoretical and empirical validation and underpinned general IT adoption studies (Zhou et al., 2012; Gangwar et al., 2014) and specific studies on tablet PCs (Anderson et al., 2006), $\mathrm{m}$-services/devices acceptance (Carlsson et al., 2006), and mobile application acceptance (Yang, 2010). Other cross-context supports of UTAUT stems, amongst others, from mobile banking (Khraim et al., 2011); internet banking (Martins et al., 2014; Tarhini et al., 2016); e-learning (Fang, 2014); webinars (Khechine et al., 2014); e-government services (Nripendra et al., 2017); internet technology (Touray \& Salminen, 2013); wikis (Toh, 2013); face-book and social media (Serbern, 2014); cloud computing (Alharbi, 2014); and smart mobile (Ally \& Gardiner, 2012). 
Studies in North and South America (Serbern, 2014; Thomas et al., 2014); Oceania (Ally \& Gardiner, 2012; Casey \& WilsonEvered, 2012); Middle East and North Africa (Nassuora, 2013; Yurdakul et al., 2014); SubSaharan Africa (Karuri et al., 2013; Tibenderana \& Ogao, 2008); Europe (Kocaleva \& Zdravev, 2014; Martins et al., 2014); and Asia (Fang, 2014; Raman et al., 2014) affirmed UTAUT framework an accurate predictor of system's acceptance. While these affirm UTAUT as one of the most widely accepted models to predict the factors that influence adoption, it is far from spanning sufficient criteria to emerge an ideal model. Specific consumer-context issues as TTF and PT seem lacking; thus, the proposed model rarely addresses all issues in different contexts. The framework captures adoption defined in terms of adopters and noneadopters based on the link between adoption and behaviour/intention, given the theoretical and empirical evidence (Ajzen, 1991; Taylor \& Todd, 1995; Foon \& Fah, 2011). Venkatesh et al. (2012) glamour for context extension and cross-country tests of UTAUT framework but rarely emphasized integration with other theories that could improve its theoretical insights. The integration of TTF is informed by empirical evidence (Junglas \& Watson, 2008; Gebauer \& Ginsburg, 2009) that shows that users are predisposed to accept technologies that fit their needs and improve performance. From Goodhue and Thompson (1995), we extend TTF to integrate task complexity (TTF1) and task interdependence (TTF2) on accounts that matching task demands and technology's capabilities positively affect adoption.

PT treats insecurity of personal details since studies (Daniel \& Jonathan, 2013; Awa et al., 2015a; Awa et al., 2015b; Awa, 2019) show that users back-out of the bargain if information privacy and security is not guaranteed. From literature (Alalwan et al., 2018; Venkatesh et al., 2012; Riffai et al., 2012), we adopt hedonic motivation of UTAUT2 in order to key into the new mechanisms of intrinsic drives (pleasures and funs derivable from using the technology), financial limitations and automaticity attached to the model. We followed the path of Dwivedi et al. (2017) to exclude the moderators from the original UTAUT model, and to identify the remaining relationships in the original UTAUT plus the inclusions of TTF and PT. Adoption has two options; a firm is either an adopter or non-adopter to reflect dichotomous explanation in figure 1. Under the proposed framework, we identified and modelled seven constructs from extant studies (Zhou et al., 2012; Oliveira et al., 2014; Venkatesh et al., 2012) to play the role of direct determinants of adoption or non-adoption.

\section{Effort Expectancy (EE)}

$\mathrm{EE}$ is an antecedent of technology adoption that crosscuts PEOU (TAM/TAM2/DTPB) and complexity (IDT) - it deals with perceived convenience of using systems. It measures the extent to which a technology is perceived simple to understand, learn or operate than its substitutes (Rogers, 2003; Davis, 1989). Mental effortlessness attracts more adoption whereas technologies with steep learning curve as well as higher mental effort, workload and stress are thought risky to adopt (Pynoo et al., 2011). Often ES is perceived very complex and difficult to implement perhaps owing to complex organizational processes (Xue et al., 2005), which limits the amount of knowledge to absorb before actual use (Yi \& Davis, 2003). Whereas some studies (Hung et al., 2009; Pynoo et al., 2011; Fang, 2014; Hung et al., 2013; Martins et al., 2014;) found EE a strong adoption predictor; others (Zhou et al., 2010; Yu, 2012; Toh, 2013; Yang, 2013) found otherwise. PEOU significantly influences attitudes towards e-Gov service and mobile e-Gov services (Hung et al., 2013), and electronic document management system (Hung et al., 2009). Arising from the preceding theoretical and empirical supports, we hypothesize the relationship.

H1: EE significantly affects adoption of ES technologies; when the effort expected to operate ES is perceived complex, adoption is purportedly low. 


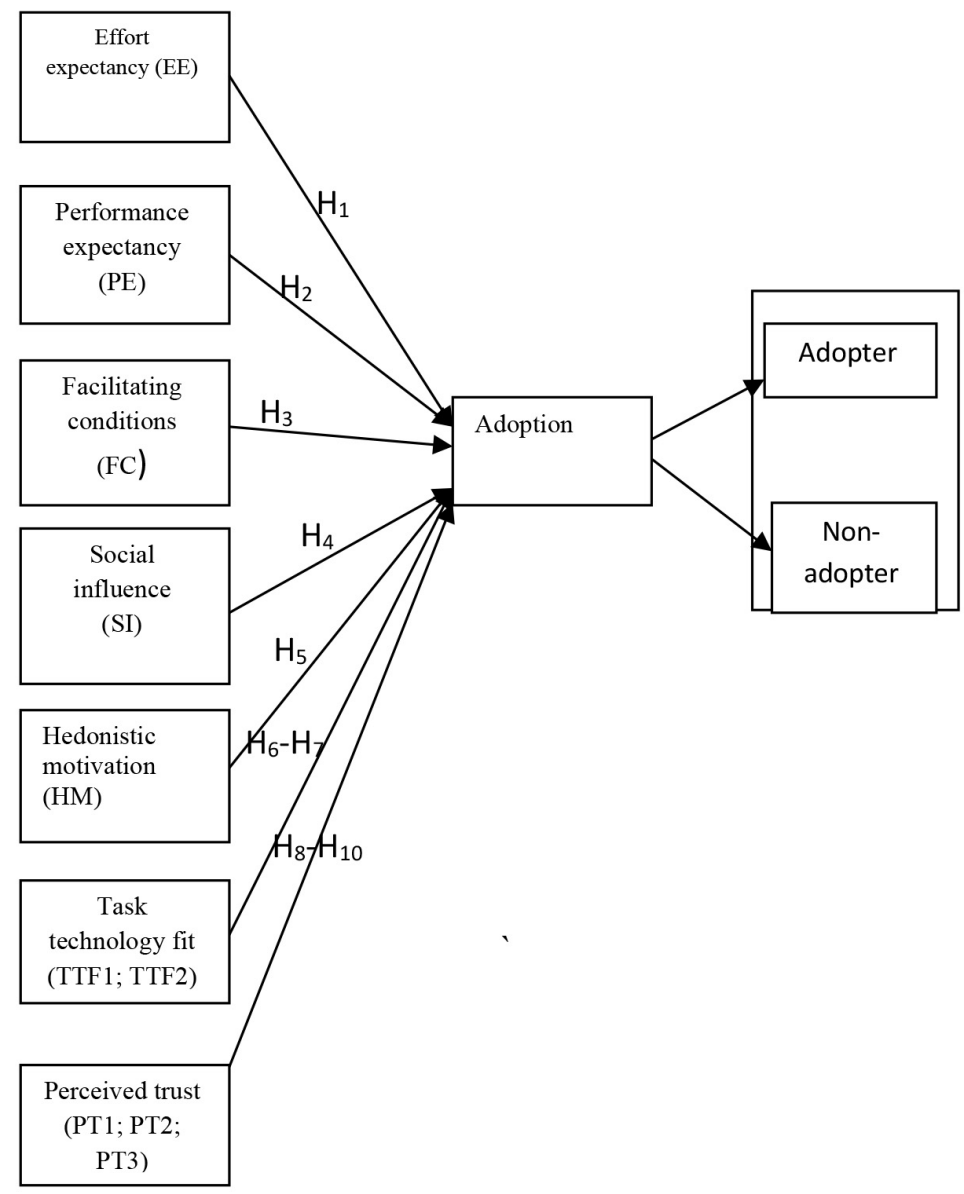

Figure 1: The proposed integrated framework

\section{Performance Expectancy (PE)}

Rooted directly to TAM (Davis, 1989) and DTPB (Taylor and Todd, 1995b), and indirectly to the utilitarian and social exchange theories, PE somewhat overlaps with extrinsic motivation (MM; Triandis, 1980), job-fit (MPCU; Thompson et al., 1994), outcome expectations (SCT; Compeau and Higgins, 1995b), relative advantage (IDT; Rogers, 2003), and PU (TAM/ TAM2; Davis, 1989). It defines innovations perceived better than extant ones in terms of saving time, money and effort, convenience, fast response and service effectiveness; and increasing real-time knowledge sharing and ultimately building of competitive advantage (Venkatesh et al., 2012; Zhou et al., 2012).
The relationship between PU and attitudinal behaviour is well investigated (Hung et al., 2009; Hung et al., 2013; Lin et al. 2011) in e-Gov adoption. Venkatesh et al. (2003) judged $\mathrm{PU}$ and relative advantage as the root constructs of $\mathrm{PE}$ and argued that $\mathrm{PE}$ represents a significant influence on attitudes. Innovations perceived to offer improved benefits over the existing ones are more likely adopted (Faaeq et al., 2014; Rogers, 2003) although other studies (Faraliza et al., 2014; Lian, 2015; Yueh et al., 2015) found no relationship between PE and use. Similarly, $\mathrm{PE}$ is a critical adoption predictor (Harfouche, 2010; Yu, 2012; Tarhini et al. 2016; Alrajawy et al., 2016) though other studies (Shiau et al., 2009; Ramdani et al., 2009; Yoon \& George, 
2013) found it one of the most significant adoption drivers. Based on the above theoretical argument, we hypothesize thus.

H2: PE significantly affects enterprises'adoption of ES solution; when the ES's perceived value is high, adoption is much more guaranteed.

\section{Facilitating Conditions (FC)}

FC involves creating enabling environment to avoid extinction (Triandis, 1980; Thompson et al., 1994). FC draws concepts from the other frameworks, including facilitating conditions (MPCU), perceived behavioral control of TPB and DTPB, and compatibility of IDT. FC emphasizes the availability of infrastructures and cognate skills (e.g., technical know-how and vendor supports) and support resources (e.g., internet/technical infrastructures, user time, and developers) needed to exploit the potentials of proposed systems (Awa et al., 2015b; Awa \& Ojiabo, 2016; Zhou et al., 2012). Tarhini et al. (2016) posit that multiple organizational programmes to promote and support ES remove adoption barriers. When PE and EE are available to predict adoption, FC becomes an insignificant adoption predictor (Venkatesh et al., 2003) though other studies (Chiu et al., 2010; Schaupp et al., 2010; Carter et al., 2012) found FC significant even when $\mathrm{EE}$ and $\mathrm{PE}$ are present. Further evidence (Arteaga et al., 2014; Gangwar et al., 2014; Moghawemi et al., 2012) confirms that top management provides support climate, communicates and reinforces corporate values through articulated vision, and thus, serves as one of the most critical adoption determinants of innovations. Conversely, studies (Singeh et al., 2013; Fang, 2014; Martins et al., 2014) found that FC does not influence use behaviour. We present our argument hypothetically below.

H3: There is a significant relationship between FC and ES adoption; when the enabling resources are available, adoption is guaranteed.

\section{Social Influence (SI)}

SI defines the psychological motives of behaviour(s) shaped by group or other peoples' influences (Ajzen, 1991; Taylor \& Todd, 1995). It tells the degree to which an individual perceives that other important persons in cohesiveness and social proximity believe in innovation. SI is composed of and resembles subjective norms (TRA, TAM2, TPB and DTPB), social status (MPCU) and image (IDT). Chinese adoption of mobile technologies (Park et al., 2007) and mobile phones (Samson \& Hornby, 1988) were informed by the need for communications, social status and attitudinal change. Younger users of communication interfaces are shaped by SI because they are at social development and learning stage of life (Ling \& Yttri, 2002) though SI has indirect impact on intention via PU (Venkatesh \& Davis, 2000). Similarly, studies (Chiu et al., 2012; Gao \& Deng, 2012; Kesharwani \& Bisht, 2012; Martins et al., 2014; Isaac et al., 2017a) found SI an important antecedent adoption factor and others (Addo, 2014; Faaeq et al., 2014; Faraliza et al., 2014; Nysveen \& Pedersen, 2014) made the contrast. For instance, Chiu et al. (2012) studied the adoption of internet sport lottery in Taiwan and found SI a critical factor across ages and internet experiences that influences lottery gaming and online betting. Gao and Deng (2012) found that SI affects PE of technology use in their study of acceptance of mobile e-book application. Consequent upon these, we propose the following hypothesis.

H4: There is significant relationship between SI and adoption of ES technologies; when SI is strong, adoption is most likely.

\section{Hedonistic Motivation (HM)}

The rational and economic entity calculates the outcomes of alternatives and invests in the most intrinsically gratifying. Venkatesh et al. (2012) factored hedonic drives into UTAUT2 and conceptualized it as intrinsic motivation or feelings of pleasure, cheerfulness, joy, enjoyment or fun from technologies. A review of consumer behavior and technology acceptance literature, as well as different IS context-studies (Cheng et al., 2006; Dickinger et al., 2006; Lin \& Hsieh, 2011; Riffai et al., 2012; Li and 
Lu, 2011; Alalwan et al., 2018) found intrinsic motivation a critical determinant of technology acceptance. Cognitive absorption was confirmed an intrinsic variable in enhancing PU (Agarwal \& Karahanna, 2000); HM found a significant adoption determinant in the choice of mobile technologies (Dickinger et al., 2006) and social networking tools (Li and Lu, 2011); and HM's indices were used in more productive manners requiring less effort and more perceived value (Cheng et al., 2006). If the HM of using an application is high, the overall benefits perceived by using it increase, and accordingly, that contribute to both the PE and the price value of using the application. Therefore, we hypothesize thus:

H5: The relationship between HM and ES adoption is significant; adoption intensifies when the decision-making group is influenced by pleasures, playfulness and fun.

\section{Task Technology Fit (TTF)}

TTF defines the extent, to which a system suits the users' interests, tasks and needs (Lin \& Wang, 2012; Lu and Yang, 2014). It explains the degree to which ES assists users to complete their required tasks in the schedule. Goodhue and Thompson (1995) posit that full picture of task characteristics in the use of any technology within organizations requires considering if the technology involved fits the task or not. TTF views task-context by its complexity and interdependences (Goodhue \& Thompson, 1995) and explains that fitting task demands that technology's fit capabilities make for faster adoption and superior services (Norzaidi and Salwani, 2009; Alatawi et al., 2012; D’Ambra et al., 2013). For task complexity, scholars (Lin \& Huang, 2008; Zhou et al., 2012) posit that technology is adopted to the extent that it streamlines the structure of complex tasks and their interrelationships in meeting the task demands. Task complexity increases proportionately with innovation adoption (DeSanctis \& Poole, 1994; Huang et al., 2006); thus, tasks with high complexity generally require a concomitant technology to facilitate progression. We hypothesize below.

H6: The complexity of tasks positively affects ES adoption; the more complex a task is the more likelihood to adopt ES provided it streamlines and simplifies them.

Task interdependence explains the degree of interconnectivity amongst tasks and organizational units (Goodhue \& Thompson, 1995), given that interconnectedness between jobs/activities explains that task's successes depend largely on the performance of intra and inter units/divisions supportive tasks (Norzaidi \& Salwani, 2009; D'Ambra et al., 2013). When people and tasks are interdependent, people seek real-time exchange of information (Alatawi et al., 2012) and show likelihood to adopt technologies with the capabilities to coordinate, develop effective task performance strategies, clarify task assignments, obtain performance feedback and make informed decisions (Goodhue \& Thompson, 1995;Andres \& Zmud, 2002). Other scholars found that tasks interdependence motivates the adoption of significant technologies to facilitate task processes more than independent tasks (Kiggundu, 1983; Norzaidi \& Salwani, 2009); thus, the effectiveness of hardware and software increases with increasing task interdependence (Shih et al., 2008; Hansen \& Kautz, 2004).

H7: There is strong relationship between task interdependence and ES adoption; when tasks are interrelated and interdependent, adoption of ES effectively integrates them smoothly.

\section{Perceived Trust (PT)}

When the perceived credibility of a technology is doubted in terms of threats of fraud and limited virtual stores, data mining, data security and personal information privacy (Awa et al., 2015a); people tend to develop cooled feet over its adoption. PT is an aspect of customercontext issues that defines individual's intention to depend on the others' integrity, benevolence and ability regardless of the trustor's inability to affect or control the other parties' behaviours 
(Gefen et al., 2003; Sriratanaviriyakul et al., 2017). The willingness to trust another is determined by established ability, honesty, and goodwill. Trust is a critical adoption factor in IS context (Awad \& Ragowsky, 2008; Cyr, 2008; Luo et al., 2010; Zhou et al., 2012; Hanafizadeh et al., 2014); trusted websites possess quality information and attract visual designs (Cyr, 2008) though Awad and Ragowsky (2008) found positive relationship between the quality of word-of-mouth and perceived trustworthiness in online bulletins. Similarly, trust is a key determinant of adoption of m-banking (Zhou et al., 2012; Hanafizadeh et al., 2014) and had significant influence on intention and PE (Luo et al., 2010).

H8: PT in handling transaction details significantly affects ES adoption.

Privacy and security as indicators of PT essentially determine user's willingness to engage in digital interactions especially when transactions move beyond the confines of simple concept and require exchanges of money and sensitive personal details (Daniel \& Jonathan, 2013; Awa et al., 2015b). Online information travels through many unsecured systems and may be intercepted and/or misused; hence, people leave websites when personal information is requested (Greene, 1997; Benassi, 1999). Privacy gives rights to control oneself information (Hugl, 2011); and to regulate disclosure and dissemination of personal information (Van De Garde-Perik et al., 2008) as well as what virtual stores make of the information afterward. Further, privacy spans control over identity anonymity, personal space privacy (the visibility of the user's online self-representation), and communication privacy (data regarding network connection, such as IP address, length of connection or user's other messages) (Sriratanaviriyakul et al., 2017; Zhang et al., 2010). When creating a site profile, disclosure is often made about the kind of data to collect, where to store them, and how to use them. Krasnova et al. (2009) found four main privacy issues: general accessibility (intercept by unauthorized parties); social threats (uncontrollable actions of other users, such as tagging or posting humiliating content on the user's profile); organizational threats (misuse of personal information by providers and/or third parties such as online marketing agencies); and identity theft. Security involves the technical apparatus employed by the provider to ensure that users' personal data is well-managed to maintain privacy policy and minimal risk of dangers.

However, mixed results besieged studies that examined the relations between privacy concerns, perceived security, and trust in web shopping. Belanger et al. (2002) found that low trust for websites attracts insecurity of transactions because a third party may hack into another's credit card and other personal details. Lack of trust in online transactions has negative relationship with customer attitude, intention to buy, and purchase behavior (Clarke, 1999; Swan et al., 1999). Trust and security issues are the most critical adoption factors (Harfouche, 2010; Yuen et al., 2010; Daniel \& Jonathan, 2013) though Tufekci (2008) found little or no relationship between online privacy concerns and information disclosure; users manage their online communities and not restricting the type of information to disclose. Boyd (2007) studied how teenagers build social network profiles and found that they fabricate their personal information such as name, age, and location and limit who sees the content as a response against their parents. Drawing from Hofstede's (1991) cultural dimensions, Cho et al. (2009) studied the impact of cultural differences on users' perception and behaviour and found that users of high individualism exhibit strong desire for privacy and show sensitivity to potential threats of intrusion, which often debars them from sharing much of their life information online. Sharbaugh and Le Trang's (2012) qualitative study found that the Vietnamese perceived privacy involves keeping personal information away from individuals who might use such information for malevolent purposes. The Vietnamese are more concern with privacy threats from individuals (e.g., friends, colleagues, or hackers/thieves) than 
from entities (e.g., government, corporations, or marketers). We formulate the hypotheses below.

H9: Adopters' concerns regarding security have positive relationship with ES adoption.

H10: Adopters' concerns regarding information privacy have positive relationship with ES adoption.

\section{Methodology}

The positivist, anti-positivist and triangulation paradigms are the intellectual traditions in the design and collection of data for any study; each is based on the assumptions about social entity (ontology), knowing reality (epistemology), and how to access what is known (methodology). Positivist orthodoxy assumes the deductivism of the natural sciences (Saunders \& Tosey, 2013; Edmonds \& Kennedy, 2012); the antipositivism emphasizes subjective meaning of social actions (inductivism); and then triangulation mixes the two, where one tradition is complementary. The paradigm chosen guides both the philosophical assumptions about the research and the selection of instruments, tools and methods (Ponterotto, 2005). To unveil oblique or orthogonal relationships between the constructs in the proposed framework and the hypothesized relationships, the study adopts ontological realism backed up by positivist epistemology and relatively deterministic and nomothetic methods because of the emphasis on observation-based objectivity and cause and effect. The choice is based on two scholarly submissions - first, Orlikowski and Baroudi
(1991) classify IS research in positivist tradition if there is evidence of quantifiable measures of variables, formal propositions, hypotheses testing and drawing of inferences (testing the theory); and second, Mukherji and Albon (2009) posit that a positive philosophy leads to a systematic and scientific approach to research and therefore lends itself to the use of quantitative methods.

\section{Population and Instrument}

A self-report questionnaire of 35 statement items targeted a purposive sample (experience and judgment guided choice of cases) of 25 managers/service executives and 35 IT operators from each of the five (300 respondents on the whole) leading fast food operators (Genesis, X1; Kilimanjaro, X2; Pepperoni, X3; Deli Spices, X4; and The Promise, X5) in Port Harcourt (see table 1 below). The questions therein relate to (1) age, (2) gender, (3) educational qualification and (4) ICT experiences, and (5) modules of ES used - demographic details (1-4) were measured using nominal scale. We had valid returns of 191 or 64 percent made up of 64 managers/executives and 127 IT operators. Further description of the respondents is reported in table 2 , where gender was 63.35 per cent males and 36.65 per cent females; age bracket varied from 16 to 65 years and ICT experience was based on years; and education was 35.60 per cent for SSCE, 29.31 per cent for diploma/NCE and 35.08 per cent for B.Sc. or above. However, the firms studied have staff strength of between 100 and 500, which is in keeping with OECD's (2002) stipulations

Table 1: Sample description

\begin{tabular}{ccccc}
\hline Enterprise & $\begin{array}{c}\text { Number } \\
\text { Administered }\end{array}$ & $\begin{array}{c}\text { Managers/ } \\
\text { Executives }\end{array}$ & IT operators & Returns \\
\hline X1 & 60 & 25 & 35 & 38 \\
X2 & 60 & 25 & 35 & 45 \\
X3 & 60 & 25 & 35 & 39 \\
X4 & 60 & 25 & 35 & 32 \\
X5 & 60 & 25 & 35 & 37 \\
\hline Total & $\mathbf{3 0 0}$ & $\mathbf{1 2 5}$ & $\mathbf{1 7 5}$ & $\mathbf{1 9 1}$ \\
\hline
\end{tabular}


for SMEs in developed and emerging nations; and the number of respondents was driven by the fact that each of these enterprises has at least 10 active branches in the city of Port Harcourt. Aside these firms being duly registered with the relevant statutory government agencies in Nigeria, they are known to use ES to integrate their operations within the units and beyond, including banks, raw material vendors, off-shore corporate customers and other stakeholders. Port Harcourt was chosen based on critical mass theory informed by cluster of ministries, parastatals, expatriates and major Nigeria's tribes owing to huge oil deposit and commercial activities.

The unobserved variables (or constructs) in the framework have well-developed measures and scales from extant IS literature. The observed items that describe the constructs were based on validated instruments from extant IS theories/studies (see table 3) though they were still reviewed by informed persons and pretested on 12 experts, and their feedbacks used to revise, and to contribute to content validity and reliability of those items. The test items were scaled on a 5-scale continuum of Likerttype measurement (from strongly agree, 5 through strongly disagree, 1) as commonly used in questionnaire-based perception studies. Post graduate students at University of Port Harcourt were drafted and coached to administer the questionnaire; they briefed participants on the aims of the study and the issues of confidentiality of information.

The focus of some questions was to measure the frequency of use of ES and average use of the system. A range of common ES systems (Microsoft, SAP, Infor, and Oracle) used by firms were offered for the survey participants to thick the ones their enterprise adopt at the time of this study though the option for non-adopters was also provided. Although participation was purely voluntary, the students encouraged responses by reminding the participants of the patronage of different units/divisions of University of Port Harcourt and promised more business accords in future. However, to minimize the fear of bias associated with non-probability samples; we rely on Chein's (1981) view to restrict and to precisely define the population.

Table 2: Subjects' demographic profile

\begin{tabular}{lcc}
\hline Category & Frequency & Percentage \\
\hline Gender: & 121 & \\
Male & 70 & 63.35 \\
Female & & \\
\hline Age bracket & 88.65 \\
16 - 25 years & 67 & 46.07 \\
26 - 35 years & 30 & 35.08 \\
36 - 45 years & 6 & 15.71 \\
46 and above & & 3.41 \\
\hline Education & 68 & 35.60 \\
Senior School Certificate Examination (SSCE) & 56 & 29.31 \\
Diploma/NCE & 67 & 35.08 \\
B.Sc. and above & & \\
\hline ICT experience & 58 & 30.37 \\
Less than 5 years & 133 & 69.63 \\
5 years and above & & \\
\hline
\end{tabular}




\section{Results}

One of the targets of this study was to unveil the specific nature of ES implementation by the sampled firms. Table 3 presents all firms in the fast food as using ES software though Oracle (32 percent) serves as the market leader with approximately one third of the market. SAP and Microsoft are the market challengers with their market control of 28 and 25 percent while Infor seems the market niche with a market share of 24 percent. However, 19 percent of the participants use other ES systems outside the options listed in the questionnaire. The free text answers provided in the questionnaire permitted responses that relate to systems mostly designed in-house or specifically made for the firms' respective industries. The other interests of the study involve more rigorous analysis and interpretation. Our test statistic involves structural equation modelling (SEM) and multiple regressions analysis (MRA). SEM combines and extends factor analysis and MRA; both are symmetric tests and report neteffect on dependent variables (Woodside, 2014) though SEM's parameter estimates lead to more accurate results by simultaneously estimating structural relations with less restrictive assumptions in selecting variables (Jöreskog \& Sörbom, 1993). Specifically, we use PLS-type SEM to assess scales' validity, and to test the proposed framework.
Scholars note that whereas the LISRELtype SEM bases on the covariance structure of the latent variables; PLS is a component-based approach for a predictive research framework (Jöreskog and Sörbom, 1993) and thus, avoids inadmissible solutions and factor indeterminacy (Fornell and Bookstein, 1982). Wold (1985) developed PLS as a multivariate path technique to handle a second generation of SEM or situations where the exogenous and endogenous variables and a series of cause-and-effect relationships exist; thus, it is suited for explaining complex relationships and for building theories. A framework like this has many exogenous latent variables with causal paths; thus, meeting the conditions of PLS. Further, the psychometric evaluation of items using factor analysis meets one of the critical conditions of path analysis (Fornell \& Bookstein, 1982; Hair et al., 2010), and with a sample of 300; SEM analysis is good, given its minimal restrictions on the sample size and residual distributions (Jöreskog \& Sörbom, 1993).

\section{Measurement model and Normality test}

We checked for skewness and kurtosis to test the univariate normality for each variable and we found that the values for each were within their thresholds. The values for all the items in the constructs support the normality of univariate distribution; the skewness values were less than the threshold of 3 and the kurtosis values less than 8 .

Table 3: ES systems adopted in sampled SMEs

\begin{tabular}{ccc}
\hline ES Systems & Absolute & Relative \\
\hline SAP & 54 & 28 \\
Microsoft & 47 & 25 \\
Oracle & 61 & 32 \\
Infor & 24 & 12.57 \\
Other ES software adopted & 19 & 9.95 \\
No ES system adopted & - & - \\
\hline
\end{tabular}

* Note: the sum of relative frequencies exceeds $100 \%$ because some participants' employers use more than one ES system. 
Table 4: Operationalization and normality test

\begin{tabular}{|c|c|c|c|}
\hline $\begin{array}{c}\text { Constructs and } \\
\text { item sources }\end{array}$ & Test items & Skewness & Kurtosis \\
\hline $\begin{array}{l}\text { Effort expectancy } \\
\text { (EE) (Cheung } \\
\text { and Vogel, 2013; } \\
\text { Martins et al., 2014) }\end{array}$ & $\begin{array}{l}\text { - I find ES software easy to learn (EE1). } \\
\text { - I find ES software quite simple and understandable (EE2). } \\
\text { - I find the ES solution flexible to interact with (EE3). } \\
\text { - I enjoy every bit of convenience with ES software (EE4) }\end{array}$ & $\begin{array}{l}-1.138 \\
-0.751 \\
-1.459 \\
-0.713\end{array}$ & $\begin{array}{c}1.149 \\
0.231 \\
-1.177 \\
0.394\end{array}$ \\
\hline $\begin{array}{l}\text { Performance } \\
\text { expectancy (PE) } \\
\text { (Martins et al., } \\
\text { 2014; Venkatesh } \\
\text { et al., 2012; Lian, } \\
\text { 2015) }\end{array}$ & $\begin{array}{l}\text { - ES software helps me to accomplish my tasks faster } \\
\text { (PE1). } \\
\text { - I easily complete my tasks with effectiveness when I use } \\
\text { ES software (PE2). } \\
\text { - I save resources using ES software (PE3). } \\
\text { - My productivity improves with ES software (PE4). } \\
\text { - Real-time interaction exists with ES software (PE5). }\end{array}$ & $\begin{array}{l}-0.731 \\
-1.559 \\
-0.863 \\
-0.811\end{array}$ & $\begin{array}{c}0.330 \\
-1.180 \\
0.304 \\
0.239\end{array}$ \\
\hline $\begin{array}{l}\text { Facilitating } \\
\text { conditions (FC) } \\
\text { (Venkatesh et al., } \\
\text { 2012; Venkatesh et } \\
\text { al., 2003) }\end{array}$ & $\begin{array}{l}\text { - Provision of the necessary internal infrastructures (FC1). } \\
\text { - Provision of hardware and software (FC2). } \\
\text { - Availability of skills and know-how (FC3). } \\
\text { - Managerial support (FC4). } \\
\text { - Training and technical assistance (FC5). }\end{array}$ & $\begin{array}{l}-1.522 \\
-0.778 \\
-1.695 \\
-0.836 \\
-0.861\end{array}$ & $\begin{array}{c}1.240 \\
0.201 \\
-1.191 \\
0.345 \\
-0.335\end{array}$ \\
\hline $\begin{array}{l}\text { Social influence (SI) } \\
\text { (Venkatesh et al., } \\
\text { 2012; Lu \& Yang, } \\
\text { 2014) }\end{array}$ & $\begin{array}{l}\text { - My family encourages me to use ES solution (SI1). } \\
\text { - My close peers influence my decision to use (SI2). } \\
\text { - Some of my co-workers say it is a good business to use } \\
\text { ES software (SI3). } \\
\text { - Some experts I know encouraged me to use it (SI4). }\end{array}$ & $\begin{array}{l}-1.632 \\
-0.531 \\
-1.699 \\
-0.743\end{array}$ & $\begin{array}{r}1.145 \\
-0.723 \\
1.107 \\
0.894\end{array}$ \\
\hline $\begin{array}{l}\text { Hedonistic } \\
\text { motivation (HM) } \\
\text { (Venkatesh et al., } \\
\text { 2012) }\end{array}$ & $\begin{array}{l}\text { - Using ES is fun (HM1). } \\
\text { - Using ES is enjoyable (HM2) } \\
\text { - Using ES is entertaining (HM3) }\end{array}$ & $\begin{array}{l}-1.532 \\
-0.643 \\
-1.795\end{array}$ & $\begin{array}{l}1.195 \\
0.731 \\
-1.107\end{array}$ \\
\hline $\begin{array}{l}\text { Task-technology fit } \\
\text { (TTF) (Zhou et al., } \\
\text { 2010; Lu \& Yang, } \\
\text { 2014) }\end{array}$ & $\begin{array}{l}\text { - ES software fits my work task (TTF1) } \\
\text { - ES is critical for my work task (TTF2) } \\
\text { - ES meets my work demands (TTF3) } \\
\text { - ES fits with my interests (TTF4) } \\
\text { - ES appropriate to my job (TTF5) }\end{array}$ & $\begin{array}{l}-1.922 \\
-0.853 \\
-1.995 \\
-0.834 \\
-0.844\end{array}$ & $\begin{array}{l}1.120 \\
-0.813 \\
1.007 \\
1.102 \\
0.843\end{array}$ \\
\hline $\begin{array}{l}\text { Perceived trust }(\mathrm{PT}) \\
\text { (Yu, 2012; Daniel \& } \\
\text { Jonathan, 2013) }\end{array}$ & $\begin{array}{l}\text { - I feel ES software provides transaction safety (PT1). } \\
\text { - I feel ES software provides security environment (PT2). } \\
\text { - I feel ES software provides me with privacy (PT3). } \\
\text { - I feel with ES software environmental and legal control is } \\
\text { ensured (PT4). } \\
\text { - I feel ES software creates absence of threat of fraud } \\
\text { (PT5). }\end{array}$ & $\begin{array}{l}-1.632 \\
-0.993 \\
-1.795 \\
-0.563 \\
-0.541\end{array}$ & $\begin{array}{l}1.101 \\
1.100 \\
-0.031 \\
1.124 \\
1.131\end{array}$ \\
\hline Adoption (AD) & $\begin{array}{l}\text { - I feel ES creates ubiquitous interactions within the value } \\
\text { chain (A1). } \\
\text { - I feel ES improves my firm's competitive advantage (A2). } \\
\text { - I feel ES makes my firm to be strategic and proactive in } \\
\text { action (A3). } \\
\text { - I feel ES provides my firm with real-time information } \\
\text { (A4). }\end{array}$ & $\begin{array}{l}-1.612 \\
-0.648 \\
-1.594 \\
-0.834\end{array}$ & $\begin{array}{l}1.120 \\
0.250 \\
-1.104 \\
1.108\end{array}$ \\
\hline
\end{tabular}


Model fitness (unidimensionality) was performed in the confirmatory factor analysis (CFA) followed by evaluation of items for reliability and validity. Before the framework was tested, the measures were validated and the relationships amongst factors within the proposed framework were examined. Although other tests were deemed fit, scholars (Fornell \& Larcker, 1981; Hair et al., 2010) demand for measurement model to assess convergent validity, discriminant validity and reliability of instrument before testing the hypothesized relationships in the structural model. CFA analyses the measurement model fit, and then evaluates the validity of the measurement model (Arbuckle, 2009; Awa, 2019) with maximumlikelihood method, to estimate the framework's parameters where all analyses were conducted on variance-covariance matrices (Hair et al., 2010). The maximum-likelihood confirms the unidimesionality of the measures and eliminates inappropriate items. Some indicators from the initial measurement model were deleted in order to ensure good fit between the framework and the data; we deleted one indicator at a time and then re-estimate the framework. Following the asymmetric approach (Ragu-Nathan et al., 2008; Gigerenzer \& Brighton, 2009; Woodside, 2014) and the need for more informative and more theoretically useful results of modeling $\mathrm{Y}$ for $\mathrm{X}$ variables, we thereafter randomly split $\mathrm{n}=$ 191 into two; the first set ( $\mathrm{n}=95$ cases) was used as scale refinement via maximum-likelihood and the second set $(\mathrm{n}=96$ cases $)$ serves as a hold-out sample for PLS of the measurement and structural models. The intent was to go beyond fit validities and net effects, and to test for predictive validity with holdout samples or to determine if the same factor structures were reproduced.

Though some were eliminated, all the items were loaded on their expected theoretical constructs and both the hold-out and total samples had identical factor structure. Further since we work with subjective opinions and so, we test for common method bias (CMB) using one-factor test of Harman with eight constructs (EE, PE, SI, FC, TTF, PT, HM, and AD) and 35 scale items (Podsakoff et al., 2003). The test tells the existence of common method variance when one factor accounts for most of the covariance in the dependent and independent variables. The factor analysis of the scales unveiled that factors explained above 70 percent $(n=191)$ of the variance with the first factor explaining 22 percent and the last 2.7 percent of the total variance; confirming no threat of $\mathrm{CMB}$ as no single factor explained majority of the variance. To assess the model goodness-of-fit, we follow the instructions of Hair et al. (2010) to consider some fit indices for the measurement and structural models. Rana et al. (2017: 560) posit that the "descriptive fit statistics compare a specified model to a baseline model, typically the independence model, with a view to showing the superiority of the proposed model."

Table 5: Fit indices for measurement and structural models

\begin{tabular}{llll}
\hline \multicolumn{1}{c}{ Fit indices } & Benchmark & $\begin{array}{c}\text { Initial } \\
\text { measurement } \\
\text { model }\end{array}$ & $\begin{array}{c}\text { Modified } \\
\text { measurement } \\
\text { model }\end{array}$ \\
\hline CMIN/df & $\leq 3.000$ & 2.586 & 1.774 \\
Goodness-of-fit index (GFI) & $\geq 0.90$ & 0.901 & 0.911 \\
Adjusted goodness of fit index (AGFI) & $\geq 0.80$ & 0.901 & 0.922 \\
Normed fit index (NFI) & $\geq 0.90$ & 0.904 & 0.921 \\
Comparative fit index (CFI) & $\geq 0.90$ & 0.910 & 0.914 \\
Root mean square error of approximation & $\leq 0.08$ & 0.044 & 0.040 \\
(RMSEA) & & & \\
Tucker-Lewis index (TLI) & $\geq 0.900$ & 0.902 & 0.924 \\
\hline
\end{tabular}


Table 4 reports the chi-square $\{\chi 2 / \mathrm{df}(\mathrm{p})\}$, GFI, AGFI, NFI, CFI, RMSEA, TLI and CFI, and the relative adequacy established for the model's fit to confirm the suitability of examining the individual path coefficients to the hypotheses. The value of 1.774 for CMIN/df is significant at $\mathrm{p}$-value of 0.000 . Similarly, other fit indices of the modified measurement model in the table were within their recommended thresholds. CFI is one of the most stable and robust incremental fit indices (Anderson \& Gerbing, 1988); CFI and GFI must measure at least 0.90 each (Hoyle, 1995) whereas AGFI must measure at least 0.80 (Chin \& Todd, 1995). RMSEA parsimoniously adjusts the index (Hooper et al., 2008) and measures the discrepancy per degree of freedom (Steiger \& Lind, 1980); although its values lie between 0.08 and 0.10 , a good fit is preferred to be below a more restrictive threshold of 0.08 (Browne \& Cudeck, 1993; Rana et al., 2017). For cross-loadings on factors and assurance of absence of multi-collinearity, we use tolerance test, Variance Inflation Factor (VIF), and DurbinWatson range. With VIFs less than 10 and the tolerance levels above 0.4 in the collinearity diagnostics (see table 6), none of the observed items showed high cross-loading threat on exogenous factors not intended to measure.
The Durbin-Watson value of 1.848 confirms absence of autocorrelation in the data set. We inspect and measure construct validity using the convergent and discriminant validities; for convergent validity, all the undeleted items had significant standardized regression weights with their latent constructs. Further, convergent validity is confirmed (see table 6) because AVE for every factor is greater than Fornell and Larcker's (1981) threshold of 0.5 (the latent variables account for 50 per cent of the variance of the indicators) for both full data set and holdout sample and statistically significant at $p$-value of less than 0.0001; and the standardized path loadings, which are indicators of the degree of association between the underlying latent factor and each item are statistically significant at greater than 0.7 (Zhang et al., 2005; Awa, 2019). The discriminant validity compared the AVE of each construct with the shared variances between it and all other constructs (Sanchez \& Roldan, 2005); thus, the square root of a construct's AVE must be larger than the interconstruct correlations to ensure discriminant validity (Fornell \& Larcker, 1981). A higher AVE than shared variance for an individual construct suggests discriminant validity. 


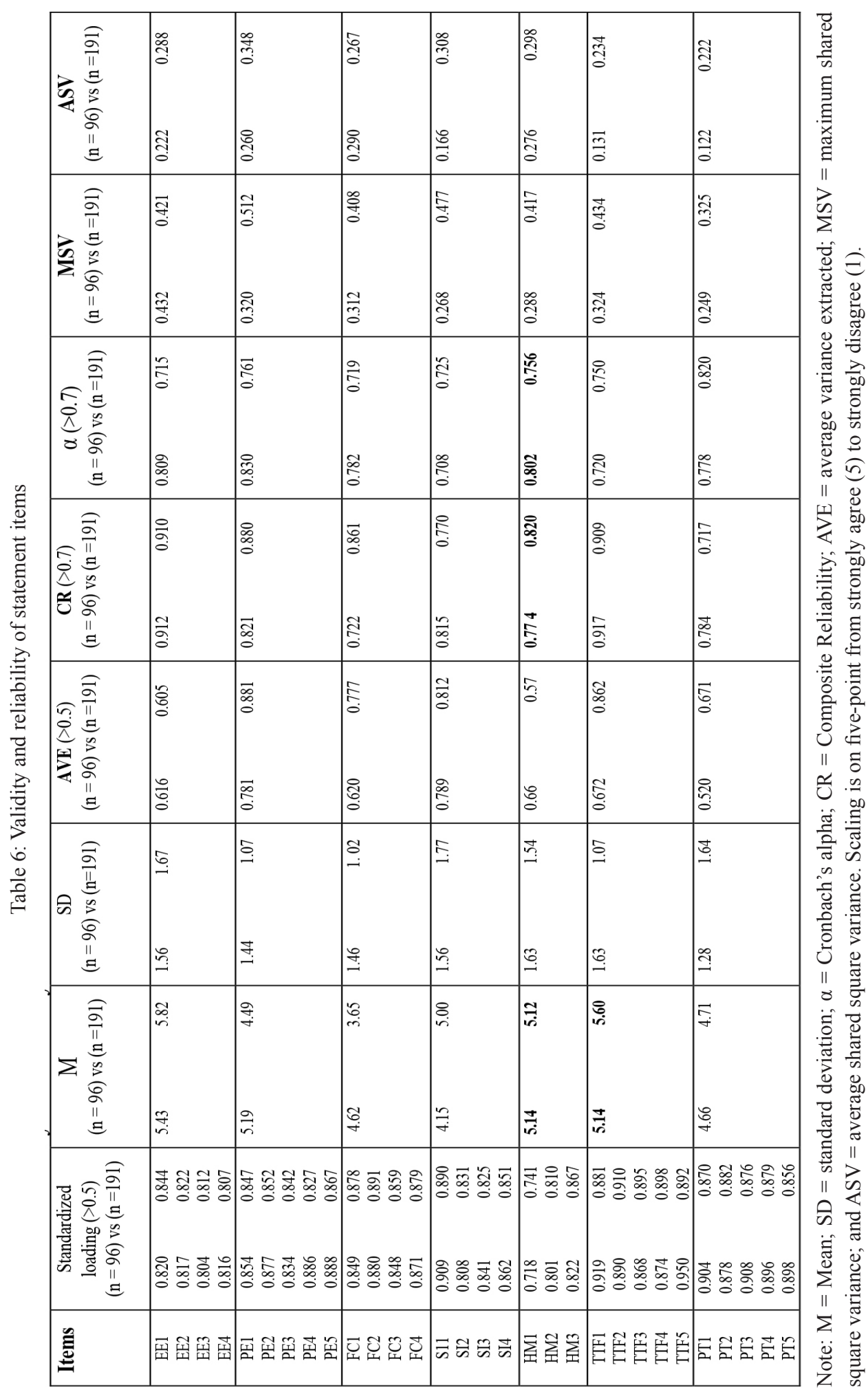


Discriminant validity is confirmed for the two data sets because the square roots of the AVE in the diagonal exceed the correlation between other constructs; and therefore, show high oblique and non-orthogonal relationships amongst themselves. Hair et al. (2010) posit that discriminant validity is supported if the MSV is less than AVE and ASV is less than AVE. These are evidenced in table 6. Construct reliability was tested to ensure adequate level of scales reliability using Cronbach's alpha, composite reliability (CR), and AVE. The statistical findings show that the psychometric assessment of survey instruments and scales confirmed internal consistency (Nunnally, 1978; Zhang et al., 2005) through inter-item consistency measure of Cronbach's coefficient and CR. Constructs' CR is similar to and superior to Cronbach's test because it considers the actual factor loadings instead of assuming an equal weight for each item (Fornell \& Larcker, 1981). Hair et al. (2010) suggest CR should be at least 0.6 and preferably a minimum of 0.7 as suggested by Nunnally (1978). The Cronbach's and CR's values were above the benchmark of 0.7 , suggesting that the multi-item observed scales were satisfactory in describing the relevant latent variables.

\section{Structural Model}

The study framework presents an overview of the hypothesized relationships and on accounts that the measurement model was well-validated, we proceed to structural model in PLS, which, according to Urbach and Ahlemann (2010), is a variance-based approach to model causal relationships amongst variables. The paths interpret the standardized beta weights within the structural model with bootstrapping (resampling with sub-samples) used to test the statistical significance of each path coefficient using t-test. Testing the hypotheses involves assessing the statistical significance of t-values for each of the path estimates and ascertaining the relationship amongst the variables. As expected, the test involves two structural models; one using the hold-out sample (the second data set; $\mathrm{n}=96$ cases) and the other using the entire data set ( $n=191$ cases). The $R^{2}$ of each regression equation indicates variance explained of the latent endogenous variable. The exogenous variables explain 42 percent variance in the adoption of ES software $\left(\mathrm{R}^{2}=0.422\right)$; thus, other factors account for the rest. When $\mathrm{n}=$ 191, the exogenous variables explain 72 percent variance in the adoption. Implicit is that hedonic drive does contribute to the variance explained in the full-data set and hold-out sample.

Table 8 shows that the path coefficients to adoption overlapped (for $\mathrm{n}=96 ; \mathrm{n}=191$ ) in the structural model were statistically supported though complexity to adoption had negative significant coefficients. In the order of significance to predicting ES adoption, the study shows FC $(\beta=0.249, p<0.05 ; \beta=$ $0.255, p<0.01)$, PT2 $(\beta=0.233, p<0.001 ; \beta$ $=0.243, p<0.01)$, TTF2 $(\beta=0.226, p<0.01$; $\beta=0.220, p<0.05), \mathrm{EE}(\beta=0.211, p<0.05$; $\beta=0.218, p<0.05)$, SI $(\beta=0.210, p<0.01 ; \beta$ $=0.214, p<0.001)$, PT1 $(\beta=0.288, p<0.05$;

Table 7: Collinearity diagnostics and construct correlations

\begin{tabular}{ccccccccccccc}
\hline & Mean & SD & Tolerance & VIF & AD & EE & PE & FC & SI & HM & TTF & PT \\
\hline AD & 4.91 & 1.58 & - & - & 0.837 & & & & & & & \\
EE & 4.77 & 1.55 & 0.745 & 2.33 & 0.434 & 0.878 & & & & & & \\
PE & 3.70 & 1.61 & 0.755 & 1.10 & 0.313 & 0.427 & 0.939 & & & & & \\
FC & 3.57 & 1.44 & 0.856 & 3.89 & 0.377 & 0.362 & 0.526 & 0.881 & & & & \\
SI & 3.11 & 1.59 & 0.639 & 3.54 & 0.342 & 0.345 & 0.476 & 0.457 & 0.901 & & & \\
HM & 3.48 & 1.65 & 0.672 & 2.88 & 0.416 & 0.304 & 0.402 & 0.441 & 0.541 & 0.870 & & \\
TTF & 4.12 & 1.77 & 0.768 & 1.82 & 0.423 & 0.467 & 0.452 & 0.482 & 0.457 & 0.819 & 0.801 & \\
PT & 3.05 & 1.73 & 0.653 & 2.49 & 0.399 & 0.334 & 0.462 & 0.362 & 0.440 & 0.517 & 0.728 & 0.899 \\
\hline
\end{tabular}


$\beta=0.209, p<0.01), \operatorname{PE}(\beta=0.196, p<0.001$; $\beta=0.204, p<0.01)$, and HM $(\beta=0.075, p<$ $0.01 ; \beta=0.055, p<0.001)$. Finally, TTF1 $(\beta$ $=-0.198, p<0.01 ; \beta=-0.187, p<0.01)$ had significant negative coefficient, indicating that the variables' ( $\mathrm{X}$ and $\mathrm{Y}$ ) units are situated on the regression line; unit increases in complexity perfectly predicts a lowering adoption likelihood or vice versa. Nevertheless, all the hypotheses were statistically confirmed and with $\mathrm{R}^{2}$ of 57 percent, the endogenous factors explained about 57 percent of adoption behaviour. Without PT and TTF in the proposed model, the model accounted for a variance of 39.10 percent and with inclusion of PT and TTF in the same structural model, it surged to 57 percent; the structural model assumes stronger power to predict adoption when PT and TTF are factored into the framework.

\section{Discussion}

This paper analysed the adoption of ES software by fast food enterprises operating in Nigeria. It proposed a UTAUT that integrates the constructs of TTF and PT as antecedent variables and repositions consumer-context and/or consumer need-fit. The framework netted ten theoretically developed hypotheses and the validity and reliability of items as well as model fitness and normality tests were conducted before using the path coefficients to test the framework and the hypothesized relationships. Our statistical results show that it is obvious that the exogenous factors examined in the proposed model have attained an acceptable predictive power on the endogenous factor - adoption (57 percent); that is, the exogenous factors explained about 57 percent of the behaviour of the endogenous factor and that, other factors explain the rest of the behaviour of the endogenous factor. In other words by integrating TTF and PT with some UTAUT2 factors, the $\mathrm{R}^{2}$ value extracted for adoption increases to 57 percent and was greater than the thresholds proposed by scholars (e.g., 40 percent for Straub et al., 2004; 30 percent for Kline, 2011); thus, supporting TTF and PT as external factors within the conceptual model. Further, the 57 percent variance slightly akin the values accounted for by similar UTAUT studies

Table 8: Path coefficients and hypotheses testing

\begin{tabular}{|c|l|l|l|r|r|r|c|}
\hline $\begin{array}{c}\text { Construct } \\
\text { relationship }\end{array}$ & \multicolumn{1}{|c|}{$\begin{array}{c}\text { Standardized } \\
\text { regression weight } \\
(\mathrm{n}=96)\end{array}$} & \multicolumn{2}{c|}{$\begin{array}{c}\text { Critical Ratio } \\
(\mathrm{CR}) \\
(\mathrm{n}=96)\end{array}$} & \multicolumn{2}{|c|}{$\begin{array}{c}\text { Sig } \\
(\mathrm{p} \text {-value }) \\
(\mathrm{n}=96)\end{array}$} & vs (n=191) & Decision \\
\hline $\mathrm{EE} \rightarrow \mathrm{AD}$ & $0.211^{* *}$ & $0.218^{*}$ & 2.510 & 2.754 & 0.006 & 0.022 & H1-supported \\
\hline $\mathrm{PE} \rightarrow \mathrm{AD}$ & $0.196^{* * *}$ & $0.204^{* *}$ & 1.946 & 2.102 & $<0.001$ & 0.004 & H2- supported \\
\hline $\mathrm{FC} \rightarrow \mathrm{AD}$ & $0.249^{*}$ & $0.255^{* *}$ & 3.732 & 3.910 & 0.024 & 0.005 & H3- supported \\
\hline $\mathrm{SI} \rightarrow \mathrm{AD}$ & $0.210^{*}$ & $0.214^{* * *}$ & 2.253 & 4.551 & 0.011 & $<0.001$ & H4- supported \\
\hline $\mathrm{HM} \rightarrow \mathrm{AD}$ & $0.075^{* *}$ & $0.055^{* * *}$ & 1.070 & 1.570 & 0.007 & $<0.001$ & H5- supported \\
\hline $\mathrm{TTF} 1 \rightarrow \mathrm{AD}$ & $-0.198^{* * *}$ & $-0.187^{* *}$ & 2.170 & 1.981 & $<0.001$ & 0.004 & H6- supported \\
\hline $\mathrm{TTF} 2 \rightarrow \mathrm{AD}$ & $0.226^{* *}$ & $0.220^{*}$ & 2.991 & 2.610 & 0.005 & 0.032 & H7- supported \\
\hline $\mathrm{PT} 1 \rightarrow \mathrm{AD}$ & $0.208^{*}$ & $0.209^{* *}$ & 2.732 & 2.212 & 0.026 & 0.008 & H8- supported \\
\hline $\mathrm{PT} 2 \rightarrow \mathrm{AD}$ & $0.233^{* * *}$ & $0.243^{* *}$ & 3.212 & 3.310 & $<0.001$ & 0.005 & H9- supported \\
\hline $\mathrm{PT} 3 \rightarrow \mathrm{AD}$ & $0.189^{* *}$ & $0.206^{* *}$ & 1.889 & 2.291 & 0.007 & 0.006 & H10- supported \\
\hline
\end{tabular}

Notes: $* \mathrm{p} \leq 0.05 ; * * \mathrm{p} \leq 0.01 ; * * * \mathrm{p} \leq 0.001 ; \mathrm{NS}$ (not supported) $\mathrm{p}>0.01$ 
though many of them use behavioural intention as the endogenous factor; for instance, Luo et al. (2010) accounted 60 percent variance for behavioural intention. Thus, the major finding was that the proposed integrated UTAUT framework sufficiently predicts adoption of ES solution. The path coefficients in the structural model were statistically supported at different strengths though the path from complexity of task (for hold-out sample, $\mathrm{n}=96$; and for entire sample, $\mathrm{n}=191$ ) to adoption had negative significant coefficients. This means that a unit increase in the complexity of the application attracts less adoption likelihoods or vice versa. This is consistent with extant inquiries (Lin \& Huang, 2008; Zhou et al., 2010; Shih, 2012) that found that streamlined and simplified technologies and processes facilitate adoption.

Further, statistical results provide strong proofs that the causal path between adoption and FC was the most critical adoption determinant (with weight of $0.249, p<0.05$ for holdout sample and $0.255, p<0.01$ for the entire sample); this was followed by security concern (PT2) and task interdependent (TTF2), which were respectively the proxies of PT and TTF (see their weights for hold-out sample and the entire sample). The alternative explanation is that FC is critical not just because the organization provides the support facilities but also because majority of individuals in the contemporary IT world access internet through their personal tablets, laptops, smart-phones, or iPods. Nevertheless, adoption of ES software is most fundamental when organizations provide the necessary FCs such as $4 \mathrm{G}$ services, web connection, Wi-Fi, and secured applications.

Whereas a number of previous studies (Zhou et al., 2012; Arteaga et al., 2014; Awa et al., 2015a; Tarhini et al., 2016; Awa \& Ojiabo, 2016; Alalwan et al., 2016) have their findings parallel to this result and affirm that availability of cognate skills and support resources are key adoption drivers; others (Singeh et al., 2013; Fang, 2014) do not confirm FC a critical adoption factor simply because of the vast personal use of internet connecting facilities. The critical nature of PT2 within the framework is explained by the fact that many adopters show high sensitivity over the safety and security of their money and other transaction details. The same alternative explanation goes to PT1 and PT3 to adoption since they border on the privacy and security concerns, which are direct dimensions of trust; thus, trust motivates adoption and shapes user perception of the novelty of the technology. However, this lays credence to extant studies (Harfouche, 2010; Yuen et al., 2010; Daniel \& Jonathan, 2013; Hanafizadeh et al., 2014; Alalwan et al., 2017), which found trust and security issues most or one of the most critical adoption determinants. Further, adopters prefer spill-over to independent and new experiences and try to save costs of improving the learning and experience curves associated with unrelated settings. Studies (Goodhue \& Thompson, 1995; Andres \& Zmud, 2002; Hansen \& Kautz, 2004; Junglas \& Watson, 2008; Shih, 2012; D’Ambra et al., 2013) show that technology adoption increases with increasing tasks interdependence.

In relation to EE's path coefficients of $0.211, p<0.05$ for hold-out sample and 0.218, $\mathrm{p}<0.05$ for the entire sample, it is confirmed that $\mathrm{EE}$ is the next most critical adoption predictor. This implies that Nigerians seem concern with the ease or complexity associated with using ES and comparing and aligning that with their own extant knowledge, experience and skills. In other words, when employees perceive ES software or any other IT-based innovation to be agile with operations and easy to use and understand, frequency and duration of use surge. Prior IS/IT literature (Davis et al., 1989; Eriksson et al., 2005) opine that individual's perception of a system's usefulness to his life is strongly influenced by the extent to which the systems more advantageously requires less efforts and complexity than its incumbents. Extant studies on EE to adoption have paradoxical results; some (Yoon \& Steege, 2013; Fang, 2014; Martins et al., 2014) found EE a strong adoption determinant; and others (Zhou et al., 2010; Yu, 2012; Guo, 2015) failed to support such relationship. These mixed results show that in some contexts, EE is not a 
strong adoption driver without the awareness of the technology's usefulness. The study further shows that results of social influences (SI) accounted for statistical variance in adoption behaviour, which means that adopters are also promoters. Firm's propensity to adopt solution increases when more family members, friends, and co-workers strongly connect ES solution to improved competitive advantage. Extant studies on SI appear mixed; whereas some crosscontext studies show that SI was the least nonsignificant adoption factor and that individual necessity rather than reference group influence guides decision (Venkatesh et al., 2003; Riffai et al., 2012; Alalwan et al., 2017), others (Foon \& Fah, 2011; Kesharwani \& Bisht, 2012; Yoon \& Steege, 2013; Martins et al., 2014; Tarhini et al., 2014) show consistency with our finding.

The finding is supported by the fact that because of the newness and novelty of ES to the Nigerian market, too many adopters depend on others to reduce their perceived risks and so, many other studies that did not support SI would have emanated from contexts where strong independent experiences and knowledge about the applications already exist. The empirical results have supported the significant relationship between PE and ES adoption with regression weights of $0.196, p<0.001$ for hold-out sample and $0.204, p<0.01$ for the entire sample. The alternative explanation to this finding is that what ES can do to improve the general operational efficiency (functional utilities) of the organizations/individuals is a key decision ingredient for Nigerian market. When users find ES software more operationally useful than others or incumbent systems then they exhibit more likelihood to use it. Theoretically, this is consistent with previous studies (Yu, 2012; Venkatesh et al., 2012; Martins et al., 2014; Alalwan et al., 2014; Tarhini et al. 2014; Alalwan et al., 2017) that applied UTAUT as a theoretical foundation in their conceptual models. This result contrasts those of other studies (Faraliza et al., 2014; Lian, 2015; Yueh et al., 2015) that found no statistically significant relationship between PE and adoption. Further and as proposed, HM (with weights of $0.075, p$
$<0.01$ for hold-out sample and $0.055, p<0.001$ for the entire sample) was empirically confirmed a critical factor influencing Nigerians' adoption of ES. This affirms that the likelihood to adopt ES software surges if peers in trying to exploit the functional utilities further perceive intrinsic factors (such as joy, entertainment, pleasure and enjoyment) when using such novel software. In Nigeria, HM shapes ES adoption behaviour because some of the met facilitating conditions (internet access; 4G, 2G, or $3 \mathrm{G}$ services, WiFi) allow sharing of fun and delights through Facebook, WhatsApp and other social media platforms. Extant IS studies (Brown \& Venkatesh, 2008; Riffai et al., 2012; Alalwan et al., 2017; Alalwan et al., 2018) lay support to intrinsic motivation as a critical predictor of adoption.

\section{Conclusion}

Within the IS domain, enterprise-level adoption is a critical area of inquiry, especially amidst the challenges and fortunes associated with its adoption. ES is a state of the art IT innovation and highly differentiated technology that is besieged with socio-technical challenges though it promises almost optimistic integrated activities and ultimately, competitive advantage. The buzzing market for IT-based innovations within the SME domain affirms its consumer-driven integrative activities and the need to generate more specific knowledge and experience since none of the extant adoption frameworks is allembracing. In addition, there are a quite few studies that investigate the related issues of ES in Nigeria. Every adoption exercise is unique to the extent that decision takes place after careful analysis of factors within the environment. In order to provide insight into understanding ES adoption, we chose for this work factors within the theoretical foundations of UTUAT and UTUAT2 frameworks based on Venkatesh et al. (2012) to explain customer perspective, and extended the factors by including PT and TTF for the purpose of capturing the idiosyncrasies associated with Nigerian setting. The inclusion of PT and TTF as external factors was informed 
by previous studies (Goodhue \& Thompson, 1995; Hanafizadeh et al., 2014; Alalwan et al., 2017) that confirmed them critical adoption predictors.

Individually, UTAUT, TTF and PT frameworks are well applauded for their sound theoretical base and integrating their strength provides cumulative scholarly synergy. Based on these and review of literature as well as the need to reposition consumer need-fit, this paper proposed a framework that integrates seven critical antecedent factors within the UTAUT, PT and TTF frameworks and sought to explore how they underlie the use of ES systems. However, accounting for about 57 percent of variance in Nigeria's market adoption of ES, the overall statistical results supports the predictive validity of the proposed theoretical framework as being useful for better understanding of users' acceptance of ES software. The results provide insights into the criticality of the proposed factors; thus, there is strong evidence that all the coefficients were significant and not of equal strengths though path coefficient on complexity had negative coefficients. Within the proposed framework, FC was the most critical adoption driver, next to it was PT, and others in that order were TTF2, EE, SI, PE and HM. The negative coefficient for TTF1 indicates inverse relationship, the more the complexity, the less the adoption likelihoods or vice versa. These results show implications to theory and practice in the IS domain.

\section{Theoretical implications}

Having proposed critical context-specific factors within UTAUT, PT and TTF frameworks and studied how the factors predict Nigerian's market adoption of ES solution, this study makes substantial contribution to the body of theoretical and methodological discourse in the IS domain in general and specifically to fast food businesses. It builds framework based on appropriate theoretical foundation and captures the most critical aspects of forming adoption behaviour in Nigerian context. Venkatesh et al. (2012) used UTAUT2 to explain and predict the acceptance of mobile internet services in developed economy and therefore, this study is one of the front-line studies that integrate some UTUAT and UTAUT2 factors to inquire into ES as a new technology in fast food context of developing economies. The proposed framework steps beyond the domain of the UTAUT framework to address the consumercontext since consumers are the critical factor for firm's existence. Further, majority of extant studies (Martins et al., 2014; Zhou et al., 2010; Tarhini et al., 2016) within UTAUT or UTAUT and TTF frameworks focus on internet banking or mobile banking and so, testing the integrated UTAUT on ES provides further scholarly utility.

\section{Practical Implications}

The statistical results support the critical role of the endogenous and the exogenous factors and so, aspects relating to these factors must be the decision focus of fast food firms that attempt to motivate customers to use ES solutions. Managers/owners, ICT consultants and vendors are informed of the significance of the various adoption factors.

- Managers/owners are encouraged by the findings to create enabling environment and invest in IT infrastructure and skills as well as customer service centres since FC is the most critical adoption factor.

- ICT consultants and vendors are expected to update ES software to integrate units, processes and activities cost-effectively and to assure fit between tasks and system's functionalities as well as security of details and user friendliness in order to keep up with tasks interdependence, trust and effortlessness.

- ICT consultants and vendors should ensure that the ES software is able to perform its intended tasks efficiently, secure customers' details, and align with existing systems, knowledge, and experiences.

- The findings of this study aid vendors and ICT consultants to encourage incumbent and potential customers to form social media community (using face-book, 
Instagram, twitter, YouTube, blogs, wikis, and SMS messages) and esprit-de-corps for group norms in order to encourage posting of attractive videos on ES operational break-through and promote adoption and hedonistic values amongst members.

- Further, the findings force ICT consultants and vendors to improve the quality of ES to reflect user aspirations and needs; they should provide user manual on systems manipulation and the depth services expected.

\section{Limitations and Suggestions}

Notwithstanding the strength of contributions of any research efforts, especially those that used statistical methods, interpretation of findings is often besieged with some limitations; thus, giving room for further inquiries.

- The generalizability of results from nonprobabilistic sample is one limitation; selection biases may not be out of it and thus, future researchers may adopt probability sample. Similarly, some errors are unavoidable in data conversion just as all measures of the constructs represent subjective perceptions and prone to common error biases (CEBs). Further, the sample was specific and limited to Port Harcourt, thereby creating room for caution and perhaps further studies when attempting to generalize these findings across different socio-cultural environments.

- $\quad$ Some UTAUT factors were integrated with TTF and PT but the explanatory power of the proposed framework still creates room for further improvement; future studies can test the framework on other IT contexts (e.g., internet banking, m-banking, cloud computing, and wikis) and across economies. Also, the proposed framework may take estimation of many variables and this can rarely be handled adequately by our small sample size.

- The influence of some factors in the framework may vary at different stages in the implementation process. Therefore, additional research may involve extending our measures and/or doing longitudinal studies in order to strengthen the direction of the causality since cross-sectional data often imply that the causal relationships identified may vary across sectors and environments or may even lose weight and meaning overtime. It may also be possible to strengthen our findings through triangulation.

\section{Acknowledgements}

Authors would like to acknowledge the university for the facilities and support.

\section{References}

Addo, H. (2014). Using the UTAUT model to analyse students' ICT adoption. International Journal of Education and Development Using Information and Communication Technology, 10(3), 75-86.

Alalwan, A., Dwivedi, Y., \& Rana, N. (2017). Factors influencing adoption of mobile banking by Jordanian bank customers: Extending UTAUT2 with trust. International Journal of Information Management, 37, 99-110.

Alalwan, A., Dwived, Y., Rana, N., \& Algharabat, R. (2018). Examining factors influencing Jordanian customers' intentions and adoption of internet banking: Extending UTAUT2 with risk. Journal of Retailing and Consumer Services, 40, 125-138.

Alalwan, A., Dwivedi, Y., Rana, N., \& Simintiras, A. (2016). Jordanian consumers' adoption of Tele-banking: influence of perceived usefulness, trust and self-efficacy. International Journal Bank Market, 34(5), 690-709.

Alalwan, A. A., Rana, N. P., Dwivedi, Y. K., Lal, B., \& Williams, M. D. (2015). Adoption of mobile banking in Jordan: Exploring demographic differences on customers' perceptions. In Open and Big Data 
Management and Innovation. Springer Publishing. pp. 13-23.

Alalwan, A., Dwivedi, Y., \& Williams, M. (2014). Examining factors affecting customer intention and adoption of Internet banking in Jordan. In Proceedings of United Kingdom Academy of Information Systems UKAIS conference.

Alatawi, F. Dwivedi, Y., Williams, M., \& Rana, N. (2012). Conceptual model for examining knowledge management system (KMS) adoption in public sector organizations in Saudi Arabia. Paper presented at the $t G O V$ Workshop '12 (tGOV12), West London: Brunei Universiti.

Al- Awadhi, S. \& Morris, A. (2008). The use of the UTAUT model in the adoption of e-government services in Kuwait, Proceedings of the 41st Hawaii International Conference on System Sciences, Hawaii.

Alrajawy, I., Daud, N., Isaac, O., \& Mutahar, A. (2016). Factors influence intention to use mobile learning within public universities students in Yemen. In The 7th International Conference Postgraduate Education (ICPE7), 1050-1064.

Al-Somali, S., Gholami, R., \& Clegg, B. (2009). An investigation into the acceptance of online banking in Saudi Arabia. Technovation, 29(2), 130-141.

Alvesson, M. \& Kärreman, D. (2007). Constructing mystery: empirical matters in theory Development. Academy of Management Review, 32(4), 1265-1281.

Ally, M. \& Gardiner, M. (2012). The moderating influence of device characteristics and usage user acceptance of Smart Mobile Devices. In 23rd Australasian Conference on Information Systems (ACIS), Geelong, Australia, 1- 10.

Amin, H. (2009). An analysis of online banking usage intentions: an extension of the technology acceptance model. International Journal of Business and Society, 10(1), 2740.
Andres, H., \& Zmud, R. (2002). A contingency approach to software project coordination. Journal of Management Information Systems, 18(3), 41-70.

Anderson, J., Schwager, P., \& Kerns, R. (2006). The drivers of acceptance of tablet PCs by faculty in a college of business. Journal of Information Systems Education, 17(4), 429440.

Arteaga, S., Cortijo, V., \& Javed, U. (2014). Students' perceptions of Face-book for academic purposes. Computers \& Education, 70(1), 138-149.

Ajzen, I. (1991). The theory of planned behaviour. Organizational Behaviour and Human Decision Processes, 50(2), 179211.

Anderson, J. \& Gerbing, D. (1988). Structural equation modelling in practice: a review and recommended two-step approach. Psychological Bulletin, 103(3), 411-423.

Arbuckle, J. (2009). Amos 18 User's Guide, SPSS Incorporated, Armonk, NY.

Awa, H. \& Ukoha, O. (2016). A model of adoption determinants of ERP within T-O-E framework. Information Technology \& People, 29(4), 901 - 930.

Awa, H., Ukoha, O., \& Emecheta, B. (2015a). Integrating TAM, TPB and TOE frameworks and expanding their characteristic constructs for e-commerce adoption by SMEs. Journal of Science and Technology Policy Management, 6(1), 76-94.

Awa, H., Baridam, D., \& Nwibere, B. (2015b). Demographic determinants of e-commerce adoption: a twist by location factors. Journal of Enterprise Information Management, 28(3), 325- 346.

Awa, H., Nwibere, B., \& Inyang, B. (2010). The uptake of electronic commerce by SMEs: A meta theoretical framework expanding the determining constructs of TAM and TOE frameworks. Journal of Global Business and Technology, 6(1), 1-27. 
Awa, H. (2018). Some antecedent factors that shape actors' adoption of enterprise systems, Enterprise Information Systems, 13(5), 1-2. DOI: $10.1080 / 17517575.2018 .1466368$

Awad, N. \& Ragowsky, A. (2008). Establishing trust in electronic commerce through online word of mouth: an examination across genders. Journal of Management Information Systems, 24(4), 101-121.

Bagozzi, R. (2007). The legacy of the technology acceptance model and a proposal for a paradigm shift. Journal of the Association for Information Systems, 8(3), 244-254.

Bandura, A. (2010). Perceived self-efficacy in cognitive development and functioning. Educational Psychologist, 28(2), 117-148.

Baruch, Y. \& Holtom, B. (2008). Survey response rate levels and trends in organizational research. Human Relations, 61(8), 11391160.

Belanger, F., Hiller, J., \& Smith, W. (2002). Trustworthiness in electronic commerce: the role of privacy, security, and site attributes. The Journal of Strategic Information Systems, 11(3), 245-270.

Benassi, P. (1999) TRUSTe: an online privacy seal programme. Communications of the ACM. 42(2), 56-59.

Brown, S. \& Venkatesh, V. (2008). Model of adoption of technology in households: a baseline Model test and extension incorporating household life cycle. MIS Quarterly, 29(3), 399-426.

Browne, M. \& Cudeck, R. (1993). Alternative ways of assessing model fit. In K. Bollen \& J. Long (Eds.) Testing Structural Equation Models. Newbury Park: Sage. p 136-162.

Carlsson, C., Carlsson, J., Hyvonen, K., Puhakainen, J., \& Walden, P. (2006). Adoption of mobile devices/services searching for answers with the UTAUT. Proceedings of the $39^{\text {th }}$ Hawaii International Conference on System Sciences, 1-10.
Casey, T. \& Wilson-Evered, E. (2012). Predicting uptake of technology innovations in online family dispute resolution services: An application and extension of the UTAUT. Computers in Human Behavior, 28(6), 2034-2045.

Chein, I. (1981). An Introduction to Sampling. In Claire Selltiz et al. (Eds.) Research Methods in Social Relations, $4^{\text {th }}$ ed., New York: Holt, Rinehart and Winston.

Chin, W. (1998). Issues and opinion on structural equation modelling. MIS Quarterly, 22, 7-16.

Chin, W. \& Todd, P. (1995). On the use, usefulness, and ease of use of structural equation modelling in MIS research: a note of caution. MIS Quarterly, 19(2), 237-246.

Cho, H., Rivera-Sánchez, M., \& Lim, S. (2009). A multinational study on online privacy: global concerns and local responses. New Media and Society, 11(3), 395-416.

Chuang, S., Luor, T. \& Lu, H. (2014). Assessment of institutions, scholars, and contributions on agile software development (20012012). Journal of Systems and Software, 93(7), 84-101.

Clarke, R. (1999). Internet privacy concern confirm the case for intervention, Communication of the ACM, 42(2), 60-67.

Compeau, D. \& Higgins, C. (1995). Computer self-efficacy: development of a measure and initial test. MIS Quarterly, 19(2), 189211.

Cyr, D. (2008). Modelling web site design across cultures: relationships to trust, satisfaction, and e-loyalty. Journal of Management Information Systems, 24(4), 47-72.

Daniel, P. \& Jonathan, A. (2013). Factors affecting the adoption of online banking in Ghana: Implications for bank managers. International Journal of Business and Social Research, 3(6), 94-108.

Davis, F. (1989). Perceived usefulness, perceived ease of use, and user acceptance 
of information technology. MIS Quarterly, 13(3), 319-340.

D’Ambra, J., Wilson, C., \& Akter, S. (2013). Application of the task-technology fit model to structure and evaluate the adoption of e-books by academics. Journal of the American Society for Information Science and Technology, 64(1), 48-64.

DeSanctis, G. \& Poole, M. (1994). Capturing the complexity in advanced technology use: Adaptive structuration theory. Organization Science, 5(2), 121-147.

Dishaw, M. \& Strong, D. (1999). Extending the technology acceptance model with task technology fit constructs. Information \& Management, 36(1), 9-21.

Edmonds, W. \& Kennedy, T. (2012). An Applied Reference Guide to Research Designs: Quantitative, Qualitative, and Mixed Methods. SAGE Publications, Inc.

Eriksson, K., Kerem, K., \& Nilsson, D. (2005). Customer acceptance of internet banking in Estonia. International Journal of Bank Marketing, 23(2), 200-216.

Faaeq, M., Alqasa, K., \& Al-Matari, E. (2014). Technology adoption and innovation of e-government in Republic of Iraq. Asian Social Science, 11(3), 135-145.

Fang, S. (2014). Using UTAUT Model to Explore the User Behaviour of E-Learning System in a Public Sector, Department of Communications Management.

Faraliza, N., Noor, M., Azmi, A., \& Ramalingam, L. (2014). The unified theory of acceptance and use of technology (UTAUT) and the goods and service tax (GST) application system. Research Journal of Applied Sciences, Engineering and Technology, 8(17), 1911- 1916.

Foon, Y. \& Fah, B. (2011). Internet banking adoption in Kuala Lumpur: an application of UTAUT model. International Journal of Business and Management, 6(4), 161-167.
Fornell, C. \& Larcker, D. (1981). Evaluating structural equations models with unobservable variables and measurement error. Journal of Marketing Research, 18, $39-50$.

Gangwar, H. Date, H., \& Raoot, A. (2014). Review on IT adoption: insights from recent technologies. Journal of Enterprise Information Management, 27(4), 488 - 502.

Gebauer, J. \& Ginsburg, M. (2009). Exploring the black box of task-technology fit. Communications of the ACM, 52(1), 130135.

Gigerenzer, G. \& Brighton, H. (2009). Homo heuristics: why biased minds make better inferences. Topics in Cognitive Science, 1, 107-143.

Goodhue, D., \& Thompson, R. (1995). Tasktechnology fit and individual performance. MIS Quarterly, 19(2), 213-236.

Greene, M. (1997). Whos zoomin who on the web? Black Enterprise, 28(3), 89-108.

Guo, Y. (2015). Moderating effects of gender in the acceptance of mobile SNS based on UTAUT Model. International Journal of Smart Home, 9(1), 203-216.

Hansen, B., \& Kautz, K. (2004), Knowledge Mapping: A Technique for Identifying Knowledge Flows in Software Organizations. Springer-Verlag Berlin Heidelberg.

Hair, J., Black, W., Babin, B., Anderson, R., \& Tatham, R. (2010), Multivariate Data Analysis, Prentice Hall, NJ, Upper Saddle River.

Hanafizadeh, P., Behboudi, M., Koshksaray, A., \& Tabar, M. (2014).Mobile-banking adoption by Iranian bank clients. Telematics and Informatics, 31(1), 62-78.

Hofstede, G. (1991). Cultures and Organizations: Software of the Mind, McGraw-Hill, New York.

Hossain, M. \& Quaddus, M. (2011). The adoption and continued usage intention 
of RFID: An integrated framework. Information technology \& People, 24(3), 236-256.

Hoyle, R. (1995). The Structural Equation Modelling Approach: Basic concepts and fundamental Issues. Thousand Oaks: Sage Publications.

Hung, S., Tang, K., Chang, C., \& Ke, C. (2009). User acceptance of intergovernmental services: An example of electronic document management system. Government Information Quarterly, 26(2), 387-397.

Hung, S., Chang, C., \& Kuo, S. (2013). User acceptance of mobile e-government services: An empirical study. Government Information Quarterly, 30(1), 33-44.

Internet World Stats. (2016). Internet Technology Usage as Percentage of Population (Yemen vs. Arab Countries). http://www. internetworldstats.com/stats5.htm.

Isaac, O., Abdullah, Z., Ramayah, T., \& Mutahar, A. (2017a). Examining the Relationship between Overall Quality, User Satisfaction and Internet Usage: An Integrated Individual, Technological, Organizational and Social Perspective. Asian Journal of Information Technology, 16(1), 100-124.

Jöreskog, K. \& Sörbom, D. (1993). LISREL 8: User's reference guide. Chicago, IL: Scientific Software International.

Junglas, I. \& Watson, R. (2008). Location-based services. Communications of the ACM, 51(3), 65-69.

Kamoun, F., \& Almourad, M. (2014). Accessibility as an integral factor in e-government web site evaluation: the case of Dubai e-government. Information Technology \& People, 27(2), 208-228.

Karuri, J., Waiganjo, P., \& Manya, A. (2013). Adoption of health information systems by health Workers in developing countries - Contextualizing UTAUT. In IST-Africa Conference Proceedings, 1-8.
Kesharwani, A. \& Bisht, S. (2012). The impact of trust and perceived risk on internet banking adoption in India: an extension of technology acceptance model. International Journal of Bank Marketing, 30(4), 303-322.

Kiggundu, M. (1983). Task interdependence and job design: test of a theory. Organizational Behavior \& Human Performance, 31(2), 145-172.

Kline, R. (2011). Principles and Practice of Structural Equation Modelling. New York: The Guilford Press.

Kocaleva, M. \& Zdravev, S. (2014). Research on UTAUT application in higher education institution. International Conference on Information Technology and Development of Education - ITRO. Zrenjanin, Republic of Serbia, 34-38.

Krasnova, H., Günther, O., Spiekermann, S., \& Koroleva, K. (2009). Privacy concerns and identity in online social networks. Identity in the Information Society, 2(1), 39-63.

Lian, J. (2015). Critical factors for cloud based e-invoice service adoption in Taiwan: An empirical study. International Journal of Information Management, 35(1), 98-109.

Lin, H., \& Lin, S. (2008). Determinants of e-business diffusion: A test of the technology diffusion perspective. Technovation, 28, 135-145.

Lin, W., \& Wang, C. (2012). Antecedences to continued intentions of adopting e-learning system in blended learning instruction: A contingency framework based on models of information system success and tasktechnology fit. Computers \& Education, 58(1), 88-99.

Ling, R., \& Yttri, B. (2002). Hyper-coordination Via Mobile Phone in Norway. In Katz, J. \& Aakhus, M. (Eds.) Perceptual Contact, Cambridge University Press, New York.

Lu, H., \& Yang, Y. (2014). Toward an understanding of the behavioural intention to use a social networking site: An extension of task- technology fit to social-technology 
fit. Computers in Human Behaviour, 34(1), 323-332.

Makokha, M., \& Ochieng, D. (2014). Assessing the success of ICT's from a user perspective: Case study of Coffee Research Foundation in Kenya. Journal of Management and Strategy, 5(4), 46-54.

Malonza, G., \& Nzuki, D. (2014). Determinants of Adoption of Enterprise Resource Planning Systems by Listed Companies in Kenya. Journal of Business and Management, 16(8), 45-50.

Martins, C., Oliveira, T., \& Popovič, A. (2014). Understanding the Internet banking adoption: A unified theory of acceptance and use of technology and perceived risk application. International Journal of Information Management, 34(1), 1-13.

Moghawemi, S., Salleh, N., Zhao, W., \& Mattila, M. (2012). The entrepreneur's perception on information technology innovation adoption: An empirical analysis of the role of precipitating events on usage behaviour. Management Policy \& Practice, 14(2), 231-246.

Mukherji, P. \& Albon, D. (2009), Research Methods in Early Childhood: An Introductory Guide. $1^{\text {st }}$ ed., SAGE Publications Ltd.

Muscatello, J., Small, M. \& Chen, I. (2003). Implementing enterprise resource planning (ERP) systems in small and midsize manufacturing firms. International Journal of Operations and Production Management, 23(8), 850 - 871.

Norzaidi, M. \& Salwani, M. (2009). Evaluating technology resistance and technology satisfaction on students' performance. Campus-Wide Information Systems, 26(4), 298-312.

Nysveen, H. \& Pedersen, P. (2014). Consumer adoption of RFID-enabled services: Applying an extended UTAUT model. Information Systems Frontiers, 3(1), 1-22.
Nunnally, J. (1978). Psychometric Theory. $2^{\text {nd }}$ ed., McGraw-Hill, New York.

OECD (2002). OECD small and medium size enterprises outlook. www.oecd.org.

Oliveira, T. \& Martins, M. (2011). Literature review of information technology adoption models at firm level. The Electronic Journal Information Systems Evaluation, 14(1), 110-121.

Orlikowski, W., \& Baroudi, J. (1991). Studying information technology in organizations: research approaches and assumptions. Information Systems Research, 2(1), 1-28.

Pew Research Centre (2013). Nations Embrace Internet \& Mobile Technology. http://www.pewglobal.org/2014/02/13/ emerging-nations-embrace-internet-mobile technology.

Ponterotto, J. (2005). Qualitative research in counselling psychology: A primer on research paradigms and philosophy of science. Journal of Counselling Psychology, 52(2), 126-136.

Pynoo, B., Devolder, P., Tondeur, J., Van Braak, J., Duyck, W., \& Duyck, P. (2011). Predicting Secondary school teachers' acceptance and use of a digital learning environment: a cross-sectional study. Computers in Human Behaviour, 27(1), 568-575.

Ragu-Nathan, T., Tarafdar, M., \& Ragu-Nathan, B. (2008). The consequences of technostress for end users and end users in organizations: conceptual development and empirical validation. Information Systems Research, 19(4), 417-433.

Rajan, C. \& Baral, R. (2015). Adoption of ERP system: An empirical study of factors influencing the usage of ERP and its impact on end user. IIMB Management Review, 27, 105-117.

Raman, A., Don, Y., Khalid, R., Hussin, F., Omar, M., \& Ghani, M. (2014). Technology acceptance on smart board among teachers in Terengganu using UTAUT model. Asian Social Science, 10(11), 84-91. 
Rana, N., Dwivedi, Y., Lal, B., Williams, M., \& Clement, M. (2017). Citizens' adoption of an electronic government system: towards a unified view. Information System Front, 19, 549-568.

Rogers, E. (2003). Diffusion of Innovations, $4^{\text {th }}$ Ed. New York: The Free Press.

Riffai, M., Grant, K., \& Edgar, D. (2012). Big TAM in Oman: Exploring the promise of on-line banking, its adoption by customers and the challenges of banking in Oman. International Journal of Information Management, 32(3), 239-250.

Saunders, B. \& Tosey, P. (2013). The Layers of Research Design. Rapport: The Magazine for NLP Professionals, 58-59.

Serbern, D. (2014). The Examination of Factors Influencing Social Media Usage by African American Small Business Owners Using the UTAUT Model, Capella University.

Sharbaugh, P. \& Le Trang, P. (2012). What's Mine Is Yours: An Exploratory Study of OnlinePersonal Privacy in the Socialist Republic of Vietnam, Unpublished work in International Communication Association 2012, Phoenix.

Shih, J. (2012). A comparison of knowledge map and keyword search in knowledge. Retrieval, 1596-1601.

Singeh, F., Abrizah, A., \& Karim, N. (2013). Malaysian authors' acceptance to selfarchive in institutional repositories: Towards a unified view. Electronic Library, 31(2), 188-207.

Sriratanaviriyakul, N., Nkhoma, M., Felipe, A., \& Cao, T. (2017). ASEAN users' privacy concerns and security in using online social networks. International Journal of Electronic Security and Digital Forensics, 9(1), 84-99.

Steiger, J. \& Lind, J. (1980). Statistically based tests for the number of common factors. Paper presented at the annual meeting of the Psychometric Society, Iowa City, IA.
Straub, D., Boudreau, M., \& Gefen, D. (2004). Validation guidelines for IS positivist research. The Communications of the Association for Information Systems, 13(1), 63.

Swan, J., Bowers, M., \& Richardson, L. (1999). Customer trust in the salesperson: An integrative review and meta-analysis of the empirical literature. Journal of Business Research, 44(2), 93-107.

Tarhini, A., El-Masri, M. Ali, M., \& Serrano, A. (2016). Extending the UTAUT model to understand the customers' acceptance and use of internet banking in Lebanon: A structural equation modeling approach. Information Technology \& People, 29(4), 830-849.

Tarhini, A., Hone, K., \& Liu, X. (2014). The effects of individual differences on e-learning users' behaviour in developing countries: a structural equation model. Computers in Human Behaviour, 41(1), 153-163.

Taylor, S., \& Todd, P. (1995). Assessing IT usage: the role of prior experience. MIS Quarterly, 19(4), 561-570.

Thomas, T., Thakur, D., Jackman, G., Thomas, M., Gajraj, R., Allen, C., \& Tooma, K. (2014). Measurement invariance of the UTAUT constructs in the Caribbean. International Journal of Education and Development Using Information and Communication Technology, 10(4), 102127.

Thompson, R., Higgins, C., \& Howell, J. (1991). Personal computing: toward a conceptual model of utilization. MIS Quarterly, 15(1), 125-143.

Tibenderana, P. \& Ogao, P. (2008). Acceptance and use of electronic library services in Ugandan Universities. Proceedings of the 8th ACM/IEEE-CS Joint Conference on Digital Libraries - JCDL '08, 323.

Toh, C. (2013). Assessing adoption of wikis in a Singapore secondary school: Using the 
UTAUT model. 2013 IEEE 63rd Annual Conference International Council for Education Media (ICEM), 1-9.

Toufaily, E., Daghfous, N., \& Toffoli, R. (2009). The adoption of 'E-banking' by Lebanesebanks: success and critical factors. International Journal of E-Services and Mobile Applications, 1(1), 67-93.

Touray, A. \& Salminen, A. (2013). The impact of moderating factors on behavioural intention towards internet: A transnational perspective. International Journal of Computer and Information Technology, 2(6), 1035-1041.

Tufekci, Z. (2008). 'Can you see me now? Audience and disclosure regulation in online socialnetwork sites. Bulletin of Science, Technology and Society, 28(1), 20-36.

Urbach, N. \& Ahlemann, F. (2010). Structural equation modeling in information systems research using partial least square. Journal of Information Technology Theory and Application, 11(2), 5-40.

Van der Heijden, H. (2004). User acceptance of hedonic information systems. MIS Quarterly, 28(4), 695-704.

Van De Garde-Perik, E., Markopoulos, P., De Ruyter, B., Eggen, B., \& Ijsselsteijn, W. (2008).Investigating privacy attitudes and behaviour in relation to personalization. Social Science Computer Review, 26(1), $20-43$.

Venkatesh, V. \& Davis, F. (2000). Theoretical acceptance extension model: field four studies of the technology longitudinal. Management Science, 46(2), 186-204.

Venkatesh, V. \& Zhang, X. (2010). Unified theory of acceptance and use of technology: US vs. China. Journal of Global Information Technology Management, 13(1), 5-27.

Venkatesh, V. \& Brown, S. (2001). A longitudinal investigation of personal computers in homes: Adoption determinants and emerging challenges. MIS Quarterly, 25(1), 71-102.

Venkatesh, V., Morris, M., Davis, G., \& Davis, F. (2003). User acceptance of information technology: toward a unified view. MIS Quarterly, 27(3), 425-478.

Venkatesh, V., Thong, J., \& Xu, X. (2012). Consumer acceptance and use of informationtechnology: extending the unified theory of acceptance and use of technology. MIS Quarterly, 36(1), 157-178.

Wang, Y. \& Shih, Y. (2009). Why do people use information kiosks? A validation of theunified theory of acceptance and use of technology. Government Information Quarterly, 26(1), 158-165.

Williams, M., Rana, N. \& Dwivedi, Y. (2015). The unified theory of acceptance and use of technology (UTAUT): a literature review. Journal of Enterprise Information Management, 28(3), 443-488.

Wold, H. (1985). Partial least squares. In Samuel K. and Normal, L. (Eds.) Encyclopaedia of Statistical Sciences, 6, New York: Wiley, 581-591.

Woodside, A. (2014). Embrace perform model: complexity theory, contrarian case analysis and multiple realities. Journal of Business Research, 67, 2495-2503.

Xue, Y., Liang, H., Boulton, W., \& Snyder, C. (2005). ERP implementation failures in China: case studies with implications for ERP vendors. International Journal of Production Economics, 97(3), 279-295.

Yahchouchi, G. (2009). Employees' perceptions of Lebanese managers' leadership styles and organizational commitment. International Journal of Leadership Studies, 4(2), 127140.

Yang, S. (2013). Understanding undergraduate students' adoption of mobile learning model: a perspective of the extended UTAUT2. Journal of Convergence Information Technology, 8(10), 969-979. 
Yurdakul, I., Ursavas, O., \& Isciturk, G. (2014). An integrated approach for pre-service teachers' acceptance and use of technology: UTAUT-PST Scale. Eurasian Journal of Educational Research, 1(55), 21-36.

Yi, M. \& Davis, F. (2003). Developing and validating an observational learning model of computer software training and skill acquisition. Information System Research, 14(2), 146-169.

Yoon, T. \& George, J. (2013). Why aren't organizations adopting virtual worlds? Computers in Human Behaviour, 29, 772790.

Yu, C. (2012). Factors affecting individuals to adopt mobile banking: empirical evidence from the UTAUT model. Journal of Electronic Commerce Research, 13(2), 104-121.

Yuen, Y., Yeow, P., Lim, N., \& Saylani, N. (2010). Internet banking adoption: comparing developed and developing countries. Journal of Computer Information Systems, 51(1), 52-61.

Zhang, Z., Lee, M., Huang, P., Zhang, L., \& Huang, X. (2005). A framework of ERP systems implementation success in China: An empirical study. International Journal of Production Economics, 98(1), 56-80.

Zhang, C., Sun, J., Zhu, X., \& Fang, Y. (2010). Privacy and security for online social networks:challenges and opportunities. Network, 24(4), 13-18.

Zhao, F., Scavarda, A., \& Waxin, M. (2012). Key issues and challenges in e-governmentdevelopment: an integrative case study of the number one e-City in the Arab world. Information Technology \& People, 25(4), 395-422.

Zhou, T., Lu, Y., \& Wang, B. (2012). Integrating TTF and UTAUT to explain mobile banking user adoption. Computers in Human Behaviour, 26(4), 760-767. 